\title{
Do young families tend to waste their food?
}

\author{
Jangkung Handoyo Mulyo, Sugiyarto ${ }^{*}$, Hani Perwitasari, Arif Wahyu Widada, Fatkhiyah \\ Rohmah and Putri Perdana \\ Department of Agricultural Socioeconomics, Faculty of Agriculture, Universitas Gadjah Mada, \\ Indonesia
}

\begin{abstract}
While there is strong evidence about the negative consequences of food waste behaviour to the economy and environment, there might still limited information about the intention and attitude on food waste issue among people, particularly young family. The objective of this study is to understand the intention to avoid food waste among young families, as well as their personal attitudes toward food waste behaviour. The data for this study were collected by using convenience sampling method among urban young families in 4 cities, namely Medan, Surabaya, Denpasar, and Yogyakarta. The respondents of 100 young head of households aged between 24-40 years old were analyzed descriptively after measured by the Likert scale. The findings reveal strong evidence that young families have tried hard not to waste their food. As for the main intention to avoid food waste, the effort aimed to reduce food waste as much as they can, as well as to reutilize all the leftovers, appears as relevant factors needed to be improved. As for their personal attitudes toward food waste issue, the view of the society that discarding food is immoral considered as the main reason for their intention toward food waste behaviour.
\end{abstract}

\section{Introduction}

Food waste is a problem faced by households because of ineffective and inefficient food consumption management. According to [1] food waste refers to a decrease in the quantity or quality of food resulting from decisions and actions taken. Alternative choices and decisions that are ultimately taken in an effort to reduce food waste are related to individual attitudes and behavior [2]. Factors that can influence food waste behavior by indirectly influencing consumer behavior including living conditions and geographic access to transportation and shops that affect the daily routine of food waste behavior. Poor knowledge, skills, and behaviors related to meal planning can increase food waste accumulation [3-5]. Moreover, cultural and geographical factors can influence these attitudes and behaviors [6].

One of the cultures that influence decisions to reduce food waste is the existence of various traditional rituals that use food as offerings or alms. Offerings are part of the culture and religious teachings adopted, one of which occurs in the Hindu community on the island of Bali. As part of Balinese culture, offerings are generally in the form of flowers, leaves, fruits, coconut and other natural materials [7-9]. The offerings also contain nuts and

\footnotetext{
*Corresponding author: sugiyarto.pnugm@ugm.ac.id
} 
foodstuffs that have been processed into traditional cakes and rice. Apart from cultural influences, food loss which is commonly called food waste is also related to individual consumption behavior [10]. This uneaten food generally occurs at the household level. However, the condition of uneaten food can also occur in other places, such as restaurants, cafes, banquets (parties), and canteens (universities, offices, industries, and so on). The factors that cause food not to be consumed in the canteen are one of the reasons because the portion size of the food served is too large or too much, so that consumers tend to set aside some of the food, as well as the lack of consumer behavior practices to bring home the food they set aside $[11,12]$.

Food waste that occurs in universities, offices and industries is certainly carried out by young people or people who are in their productive age. But on the other hand, the trend to live a healthy life by consuming environmentally friendly foods and in sufficient portions is also carried out by young people. Desirable food quality might relate to taste, health, convenience and process characteristics such as the social or environmental impact of production [13]. Foods potentially more sustainable are sourced from more environmentally friendly farming, animal husbandry with improved animal welfare, local, authentic and small-scale farming and food production. Apart from being environmentally friendly, young people also have the view that reducing food waste means saving household expenses. "Reducing the amount of money wasted" as the key motivator that would spur them to reduce food waste. Furthermore, the over purchase of food was the most consistent reason why food was thrown out, suggesting a recognition that this is a money wasting behavior. Then the positive message of reducing food waste to save money [14]. Thus, it is necessary to conduct a study whether young people have the intention to avoid food waste among young families, as well as their personal attitudes toward food waste behavior

\section{Research Methods}

\subsection{Sample and Location}

This study used a sample of respondents in the form of households with a household head aged 24 to 40 years. Respondents were determined by the convenience sampling method. The number of respondents who were surveyed was 100 households. Respondents are spread across four major cities in Indonesia including Medan, Yogyakarta, Surabaya, and Denpasar. Data were collected in 2020.

\subsection{Data Analysis}

\subsubsection{Determination of young people's personal attitude and intentions in reducing food waste}

The data used were primary data obtained by survey method using a digital questionnaire with a structured question instrument with a Likert scale. Answers from the Likert Scale used are seven levels with a score of 1 to 7 for each item. In predicting personal attitudes towards food waste and intentions to reduce food waste, use the following indicators: 
Table 1. Indicator statement of personal attitudes towards food waste and intentions to reduce food waste.

\begin{tabular}{|l|c|}
\hline \multicolumn{1}{|c|}{ Indicator Statement } & Score \\
\hline Intentions to Reduce Food Waste & \\
\hline Trying to not waste food & $1-7$ \\
\hline Trying to finish the food that has been bought & $1-7$ \\
\hline Trying to produce a few leftovers & $1-7$ \\
\hline Trying to make use of all the leftovers & $1-7$ \\
\hline Average & $1-7$ \\
\hline Young People's Personal Attitude Towards Food Waste & \\
\hline Food can always be used in various ways & $1-7$ \\
\hline Throwing food away is immoral & $1-7$ \\
\hline Upset if the food ends up in the trash & $1-7$ \\
\hline Average & $1-7$ \\
\hline
\end{tabular}

Furthermore, the average score for each question item from all respondents' answers is calculated. The achievement score for each question item is then calculated in percent (\%) which is compared with the maximum score of seven. The larger value indicates the expected condition for households to have a personal attitude and good intentions towards food waste [15].

\subsubsection{Correlation of young people's personal attitude and intentions in reducing food waste}

The correlation of personal attitudes towards food waste with the intention to reduce food waste was analyzed using the Spearman Correlation. Calculation of Spearman's correlation using the following equation [16]:

$$
r_{s}=\left(\sum_{(i=1)}^{n}\left\{\left(x_{i}-\bar{X}\right)\left(y_{i}-\bar{Y}\right)\right\}\right) /\left(\left(\sqrt{ }\left(\sum_{(i=1)}^{n}\left(x_{i}-\bar{X}\right)^{2}\right) \sqrt{ }\left(\sum_{(i=1)}^{n}\left(y_{i}-\bar{Y}\right)^{2}\right)\right.\right.
$$

Description:

$r_{\mathrm{s}} \quad$ : Spearman's correlation value

$\mathrm{x}_{\mathrm{i}} \quad$ : the rank of the measurement of $\mathrm{X}$ taken on the ith individuals

$\mathrm{y}_{\mathrm{i}} \quad$ : defined similarly

The error rate used in this correlation analysis is $5 \%$. Further analysis was carried out using SPSS including the validity and reliability of the item statements.

\section{Results and Discussion}

This study examines personal attitudes and intentions to reduce food waste among young people between 24 and 40. Most of the respondents were between 29-40 years old (54\%), with an average age of 33. Many young people have completed higher education (78\%) and work as employees $(45 \%)$. In addition, most of the young people's income ranges between IDR 3,000,000 - IDR 9,000,000 (68\%), with an average income of IDR 3,000,000. 
Table 2. Participant demographics.

\begin{tabular}{|c|c|}
\hline Head of Household & $\%$ \\
\hline \multicolumn{2}{|l|}{ Age } \\
\hline $24-28$ y.o. & 17 \\
\hline $29-33$ у.о. & 35 \\
\hline $34-38$ y.o. & 29 \\
\hline$>38$ y.o. & 19 \\
\hline \multicolumn{2}{|l|}{ Education } \\
\hline $0-6$ years & 0 \\
\hline $7-9$ years & 1 \\
\hline $10-12$ years & 21 \\
\hline$>12$ years & 78 \\
\hline \multicolumn{2}{|l|}{ Main Job } \\
\hline Civil servant & 18 \\
\hline Teacher and lecturer & 4 \\
\hline Police and army & 3 \\
\hline Employees & 45 \\
\hline Self-employed & 20 \\
\hline Retired & 0 \\
\hline Other & 10 \\
\hline \multicolumn{2}{|c|}{ Household Income (IDR/month) } \\
\hline$<3,000,000$ & 14 \\
\hline $3,000,000-6,000,000$ & 68 \\
\hline $6,100,000-9,000,000$ & 12 \\
\hline$>9,000,000$ & 6 \\
\hline
\end{tabular}

\subsection{Intentions to Reduce Food Waste}

Based on Ajzen's Theory of Planned Behavior, intention plays as key predictor of individuals' behavior. [17] stated clearly that promoting effective anti-food waste behavior can be encouraged by some intentional processes. Generally, people's intention not to waste food will be greater when it is strongly perceivable that people should not waste food [17-19]. The categorization of these scores are: (i) achievement score $<43 \%$ is considered as low, (ii) $43 \% \leq$ achievement score $<69 \%$ as moderate, and (iii) achievement score $\geq$ $69 \%$ as high.

Table 3 indicates people's strong intention not to waste food as can be seen from the achievement scores of all four statements. The first statement, the consumers' intention not to waste food has the highest score among the four items, partly due to the fact that most people feel bad and guilty when discarding food. In line with this, [20] concluded on their study that the feeling of being guilty presents when consumer wasting or discarding consumable food. This feeling has encouraged consumers to reduce food waste in order to alleviate the guilt feelings. Viewed from cultural side, in rural Java for example, there is a gentle "rebuke" from parents to their children that when the child does not finish their meal, their chicken (pet) will die. This has clear message that appreciating food has been taught 
by rural Javanese to their generation since childhood by introducing negative feeling when throwing food away. Meanwhile, in terms of Islamic religious orders, there is an appeal for Muslims to consume enough food but not extravagant (QS. Al A'raf: 31 and QS. Al Isra':27).

Table 3. Intentions to reduce food waste.

\begin{tabular}{|l|c|c|c|}
\hline \multicolumn{1}{|c|}{ Items/measuring indicators } & Score & Achievement (\%) & Category \\
\hline Trying to not waste food & 6.55 & 93.57 & High \\
\hline Trying to finish the food that has been bought & 6.16 & 88.00 & High \\
\hline Trying to produce a few leftovers & 6.10 & 87.14 & High \\
\hline Trying to make use of all the leftovers & 6.12 & 87.43 & High \\
\hline Average score & $\mathbf{6 . 2 3}$ & $\mathbf{8 9 . 0 4}$ & High \\
\hline
\end{tabular}

The last two intention items, trying to produce a small leftover food, and trying to use all leftovers, had a lower score than the other two even though it still categorized as high achievement. For the statement of trying to produce a small leftover food, this situation is often in conflict with the custom of traditional and or religious ceremonies that usually serving food in abundance. The customs such as ceremonies for the birth of children, birthday celebration, weddings, funeral ceremony, and pray for the deceased (tahlilan) and religious holidays (Eid Mubarak, Christmas, Galungan, etc.) are usually attended by families, relatives, neighbors, and friends, so that it needs more foods to be served. There is seldom effort made for limiting the amount of food served to invited guests due to feeling of inferiority as well as not acting as good provider for the guests. As consequence, this has led to encouragement for the hosts to serve food as best and as complete as they can afford which unluckily also led to undesired actions of wasting food. Similar findings also reported by [21] that in South Africa, social activities related to cultural practices (mainly weddings and funeral ceremonies) has increased the amount of food waste to be disposed at the landfill sites which is remain a serious challenge for the country to solve.

The intention to reduce food waste in the form of effort addressed to utilize all leftovers needs to be improved, especially targeted to the millennial generation and young families. They are considered as potential targets for anti-food waste campaign because they are more open to information and mostly well educated, but at the other side they quite "separate" from the local wisdom and habits related to the food waste reduction effort that have long been practiced by most rural people. The form of effort of reutilizing the leftovers including: i) consume the leftovers on the next day by re-cooking food (usually refrying) or utilize the leftovers as additional ingredients for other dishes, ii) distributed to relatives or neighbors, if the food is not used and have not been consumed in good conditions, and iii) given to their pets. However, these forms of efforts are facing more challenges nowadays, when foods are more accessible and affordable, as well as the improvement of the people's awareness toward health issues, there is a tendency for people to not optimally reutilize the leftovers due to concerns over possible health risks [22], [23] and or simply disgusted with such idea of leftovers reutilization [22].

\subsection{Young People's Personal Attitude Towards Food Waste}

Based on table 4, the personal attitude towards food waste of young people is in the high category. That is, young people have the attitude not to waste food. They will try to use leftover food in various ways, such as warming the food the next day or cooking it back into another menu because it can still be consumed and not harmful to health. This result 
consistent with the results of research [24] which states that age will positively affect personal food waste attitudes, intentions to reduce food waste, and behavior not to waste food. However, according to [10] and [25] young people tend to produce more food waste. The average age of the young people in this study is 33 years, but the average income is still around IDR 3,000,000 and is already married. It can make young people more careful in managing finances so that their attitude towards food waste is high and they try to reduce food waste.

Table 4. Young People's Personal Attitude toward Food Waste.

\begin{tabular}{|l|c|c|c|}
\hline \multicolumn{1}{|c|}{ Items/measuring indicators } & Score & Achievement (\%) & Category \\
\hline Food can always be used in various ways & 6.31 & 90.14 & High \\
\hline Throwing food away is immoral & 6.56 & 93.71 & High \\
\hline Upset if the food ends up in the trash & 6.35 & 90.71 & High \\
\hline Average score & $\mathbf{6 . 4 1}$ & $\mathbf{9 1 . 5 2}$ & High \\
\hline
\end{tabular}

Young people also think that throwing away food is immoral. Most young people (78\%) have education up to college. Thus, the insight is quite broad where they perceive that there are still many people who need food, so it is unethical to waste the food they have. Their empathy is significant enough that they even get annoyed when food has to be thrown away. It can be influenced by social habits and norms [26]. Table 5, which shows the significance of the spearman's rho correlation coefficient, is smaller than the $1 \%$ error rate. Thus, the higher the personal attitude possessed by young people not to waste food, the higher the intention to reduce food waste. The high intention to reduce food waste will encourage behavior not to waste food [6]. In addition, with good attitudes and intentions, young people can be given socialization and dissemination related to the negative impacts of food waste from economic, social and environmental aspects and mitigation strategies of household food waste to reduce food waste [27]-[29].

Table 5. Correlation between Young People's Personal Attitude and Intention to Reduce Food Waste.

\begin{tabular}{|l|l|l|c|c|}
\hline \multicolumn{2}{|c|}{ Correlations } & $\begin{array}{c}\text { Personal } \\
\text { Attitude }\end{array}$ & $\begin{array}{c}\text { Intention to } \\
\text { Reduce Food } \\
\text { Waste }\end{array}$ \\
\hline \multirow{2}{*}{$\begin{array}{l}\text { Spearman's } \\
\text { rho }\end{array}$} & Personal Attitude & $\begin{array}{l}\text { Correlation } \\
\text { Coefficient }\end{array}$ & 1.00 & $0.48^{* *}$ \\
\cline { 3 - 5 } & Sig. (2-tailed) & 0.00 & 0.00 \\
\cline { 2 - 5 } & $\begin{array}{l}\text { Intention to Reduce } \\
\text { Food Waste }\end{array}$ & $\begin{array}{l}\text { Correlation } \\
\text { Coefficient }\end{array}$ & $0.48^{* *}$ & 1.00 \\
\cline { 3 - 5 } & Sig. (2-tailed) & 0.00 & 0.00 \\
\cline { 3 - 5 } & $\mathrm{N}$ & 100.00 & 100.00 \\
\hline
\end{tabular}

**. Correlation is significant at the 0.01 level (2-tailed).

\section{Conclusion and Suggestion}

The intention of young families not to waste food has an average value of 6.23 (out of a maximum of 7) and is included in the high achievement category. Consumer behavior not to waste food is closely related to the teachings of religion, customs, and community culture. Consumers of young families feel uncomfortable and even feel guilty when throwing away food that is still proper for consumption so that this will motivate them not to waste food in the future. 
The personal attitude of young families towards food waste is included in the high category with an average score of 6.41 (from a maximum of 7). These results indicate that young families have an attitude not to waste food. They argue that throwing away food is immoral. Therefore, they will try to use the leftovers that are still decent in various ways, such as warming the food, and re-cooking the food into another menu. The personal attitude of young families to reduce food waste is closely related to the intention to reduce food waste.

There needs to be intensive socialization and dissemination to the community, especially young families regarding food waste, the negative impact of food waste on economic, social, and environmental aspects, the causes of food waste and the strategies needed to mitigate food waste in households.

\section{References}

1. FAO, "What is food loss and food waste?," 2021. [Online]. Available: http://www.fao.org/food-loss-and-food-waste/flw-data. [Accessed: 03-Jul-1BC].

2. M. R. Kosseva and C. Webb, Food Industry Wastes 1st Edition Assessment and Recuperation of Commodities. USA: Academic Press, 2013.

3. P. van der Werf, J. A. Seabrook, and J. A. Gilliland, Can. Geogr., 63, 3: 478-493 (2019).

4. H. Marie and C. Boks, J. Clean. Prod., 151, 380-392 (2017).

5. V. Ilyuk, J. Retail. Consum. Serv., 41, 20-30 (2018).

6. D. Evans, Sociology, 46, 1, 41-56 (2012). Yadav, S. K. Juneja, and S. Chauhan, Int. J. Eng. Technol. Sci. Res., 2, 14-19, (2015).

7. J. A. R, IOSR J. Agric. Vet. Sci., 3, 5, 01-04 (2013).

M. W. Wijaya and I. K. A. Putra, 1, 1-8 (2021).

8. J. Parfitt, M. Barthel, and S. MacNaughton, Philos. Trans. R. Soc. B Biol. Sci., 365, 1554, 3065-3081 (2010).

9. S. Puspitasari, "Solusi Permasalahan Sisa Makanan Terkait Faktor Ukuran Porsi Makanan dan Praktek Perilaku Take Home the Leftovers," 2014. [Online]. Available: https://dokumen.tips/documents/food-waste-manajemen-penyelenggaraanmakanan.html. [Accessed: 03-Jul-1BC].

10. Barbara Buchner et al., Food waste: casuse, impacts and proposals. Italy: Barilla Center For Food \& Nutrition, 2012.

11. K. G. Grunert, Eur. Rev. Agric. Econ., 32, 3, 369-391 (2005).

12. P. van der Werf, J. A. Seabrook, and J. A. Gilliland, Environ. Behav., 53, 2, 151-183 (2021).

13. L. Falasconi, C. Cicatiello, S. Franco, A. Segrè, M. Setti, and M. Vittuari, Sustain., 11, 1, 12-20 (2019).

14. D. N. Gujarati, Basic Econometric Fourth Edition. New York: McGraw-Hill/lrwin, 2003.

15. V. Stancu, P. Haugaard, and L. Lähteenmäki, Appetite, 96, 7-17 (2016).

16. D. Zainal and K. A. Hassan, Int. J. Res. Business, Econ. Manag., 3, 3, 56-71 (2019).

17. D. Szakos, B. Szabó-Bódi, and G. Kasza, Environ. Sci. Pollut. Res., 28, 19, 458024589 (2021). 
18. F. Soorani and M. Ahmadvand, Waste Manag., 98, August, 151-159 (2019).

19. L. Phasha, G. F. Molelekwa, M. I. Mokgobu, T. J. Morodi, M. M. Mokoena, and L. S. Mudau, J. Ethn. Foods, 7, 1 (2020).

20. J. Aschemann-Witzel, Curr. Opin. Food Sci., 3, 6-10 (2015).

21. Ella Graham-Rowe, D. C. Jessop, and P. Sparks, Resour. Conserv. Recycl., 101, 194202 (2015).

22. V. H. M. Visschers, N. Wickli, and M. Siegrist, J. Environ. Psychol., 45, 66-78, (2016).

23. K. Schanes, K. Dobernig, and B. Gözet, J. Clean. Prod., 182, 978-991 (2018).

24. H. S. Fami, L. H. Aramyan, S. J. Sijtsema, and A. Alambaigi, Resour. Conserv. Recycl., 143, January, 154-166 (2019).

25. R. Nunkoo, M. Bhadain, and S. Baboo, 123, 6, 2016-2035 (2020).

26. C. Priefer, J. Jörissen, and K. R. Bräutigam, Resources, Conservation and Recycling, 109. 155-165 (2016).

27. T. Soma, B. Li, and V. Maclaren, Resour. Conserv. Recycl., 168, 105313 (2021). 